\title{
Relación entre actividad enzimática y biomasa de ensambles fitoplanctónicos en el sistema pelágico
}

\author{
José L. Iriarte ${ }^{1}$, Renato A. Quiñones ${ }^{2}$, Rodrigo R. González ${ }^{2}$ \& Cynthia P. Valenzuela ${ }^{1}$ \\ ${ }^{1}$ Núcleo Científico Milenio FORECOS e Instituto de Acuicultura, Universidad Austral de Chile \\ Puerto Montt Campus, Casilla 1327, Puerto Montt, Chile \\ ${ }^{2}$ Centro de Investigación Oceanográfico para el Pacífico Sur Oriental COPAS \\ Universidad de Concepción, Casilla 160-C, Concepción, Chile
}

\begin{abstract}
RESUMEN. En ambientes de condiciones fluctuantes y drásticas, las adaptaciones fisiológicas y bioquímicas pueden llegar a ser importantes en la estructuración de ensambles fitoplantónicos. El objetivo de este estudio fue establecer si la actividad enzimática de fitoplancton, como un indicador de su metabolismo interno dominante, se relaciona con la biomasa autotrófica. Las áreas geográficas estudiadas correspondieron a: islas Shetlands del Sur (62ㅇ), bahía de Mejillones $\left(22^{\circ} \mathrm{S}\right)$ y seno de Reloncaví (413’ S). En las áreas seleccionadas y mediante una aproximación de terreno, se colectaron muestras para análisis enzimático del metabolismo intermediario del nitrógeno (nitrato reductasa y glutamina sintetasa), biomasa autotrófica y análisis de nutrientes disueltos inorgánicos. En términos de la actividad enzimática fraccionada por tamaño se observó una disminución de la actividad de nitrato reductasa $\left(b_{\mathrm{S} \text { Reloncaví }}=-0,93 ; b_{\mathrm{B}}\right.$ Mejillones $\left.=-0,65\right)$ y glutamina sintetasa $\left(b_{\mathrm{S} \text { Reloncavi }}=-0,79\right)$ con el incremento del tamaño corporal del fitoplancton. Estas pendientes, menores a $-1,0$, señalan la relativa importancia de ensambles fitoplanctónicos dominados por diatomeas en aguas costeras ricas en nutrientes inorgánicos nitrogenados. Durante el desarrollo de una floración de una especie de dinoflagelado se detectó una elevada actividad de glutamina sintetasa (GS), sugiriendo que ciertas especies de dinoflagelados prefieren las formas de nitrógeno reducido (amonio y urea) en comparación a nitrato o nitrito. La estimación, vía actividad enzimática, de la razón $f$ con valores $>0,5 \mathrm{y}<0,5$, sugiere la importante contribución de las diatomeas a la producción nueva (basada en nitrato) en comparación a los flagelados, los cuales contribuyen significativamente a la producción regenerada (basada en amonio), respectivamente.
\end{abstract}

Palabras clave: Nitrato reductasa, glutamina sintetasa, nitrógeno inorgánico, clorofila, fitoplancton.

\section{Relationship between enzymatic activity and biomass of phytoplankton assemblages in the pelagic system}

\begin{abstract}
In environments with drastically fluctuating conditions, physiological and biochemical adaptations can be important for the structuration of phytoplankton assemblages. The objective of this study was to establish whether the enzymatic activity of the phytoplankton, an indicator of its dominant internal metabolism, is related to the autotrophic biomass. The geographic study area covered the South Shetland Islands $\left(62^{\circ} \mathrm{S}\right)$, Mejillones Bay $\left(22^{\circ} \mathrm{S}\right)$, and Seno de Reloncaví (4130'S). Samples were collected in the field at the selected sites for enzymatic analyses of the intermediary nitrogen metabolism (nitrate reductase, glutamine synthetase) and autotrophic biomass, as well as dissolved inorganic nutrient analyses. In terms of the size-fractionated enzymatic activity, nitrate reductase $\left(b_{\mathrm{S} \text { Reloncaví }}=-0.93 ; b_{\mathrm{B} \text { Mejillones }}=\right.$ $-0.65)$ and glutamine synthetase $\left(b_{\mathrm{S} \text { Reloncavi }}=-0,79\right)$ activities decreased as the body size of the phytoplankton increased. These slopes, less than -1.0, indicate the relative importance of diatom-dominated phytoplanktonic assemblages in coastal waters rich in inorganic nitrogenated nutrients. Elevated glutamine synthetase activity (GS) was detected during a bloom of a dinoflagellate species, suggesting that certain dinoflagellate species prefer reduced nitrogen forms (ammonium and urea) over nitrate or nitrite. The estimate, via enzymatic activity, of the $f$ ratio with values $>0.5$ and $<0.5$ suggests, respectively, an important diatom contribution to new production (based on nitrate) as compared with the flagellate contribution, which is important to regenerated production (based on ammonium).
\end{abstract}

Key words: nitrate reductase, glutamine synthetase, inorganic nitrogen, chlorophyll, phytoplankton.

Autor corresponsal: José L. Iriarte (jiriarte@uach.cl). 


\section{INTRODUCCIÓN}

La productividad primaria en el ambiente marino es una propiedad comunitaria de compleja modelación debido a su regulación por múltiples factores, entre ellos la concentración de nutrientes y la intensidad de luz. Los macro y micronutrientes, tales como el nitrógeno, fósforo, sílice y hierro, han sido sugeridos como posibles factores limitantes del crecimiento del fitoplancton, lo que ha sido evidenciado tanto en sistemas oceánicos (Dunne et al., 1999; Tyrrel, 1999), como en sistemas costeros (Herbland et al., 1998; Hutchins \& Bruland, 1998). Aunque el concepto de "nutriente limitante" propuesto por Liebig (Liebig, 1843) establece que el crecimiento está determinado principalmente por la concentración por aquel nutriente que se encuentra menos disponible en el medio, también se han observado otros efectos, tales como reducción a nivel individual de actividades enzimáticas (e.g., enzima Rubisco, Geider et al., 1993), contenido de pigmento celular (Sosik \& Mitchell, 1991) y eficiencia fotosintética máxima (Greene et al., 1991).

Los estudios in situ de la actividad enzimática de la comunidad fitoplanctónica son escasos. Eppley et al. (1969) discutieron la importancia del potencial uso de enzimas, como la nitrato reductasa, en estudios de ecología fitoplanctónica, principalmente como indicador de la fuente de nitrógeno externo $\left(\mathrm{NO}_{3}{ }^{-}\right.$o $\left.\mathrm{NH}_{4}^{+}\right)$(Fig. 1). Estudios posteriores examinaron la potencial relación entre la actividad de la nitrato reductasa y la tasa de asimilación de nitrato en el fitoplancton marino (Collos \& Slawyk, 1976; Blasco et al., 1984), así como también entre la nitrato reductasa y variables ambientales, como $\mathrm{NO}_{3}^{-}$, $\mathrm{NH}_{4}^{+}, \mathrm{Fe}^{++}$y luz (Collos \& Lewin, 1974; Blasco \& Conway, 1982; Timmermans et al., 1994; Flynn \& Ripkin, 1999). Experimentos comparativos en condiciones de laboratorio han mostrado una mayor actividad enzimática de las nitrato/nitrito reductasas en especies de diatomeas en comparación a especies de flagelados (Lomas \& Glibert, 2000). Estas diferencias especie-específicas sugieren indirectamente que el tamaño celular puede tener un impacto importante en la actividad enzimática, principalmente debido a diferencias en la estructura celular, composición química y estado trófico (autotrófico/mixotrófico) y relación superficie/volumen $(\mathrm{S} / \mathrm{V})$. La actividad enzimática como una tasa metabólica dependiente del tamaño corporal es un área de investigación actual y relevante para mejorar el entendimiento de las tramas tróficas de los ecosistemas marinos.
En ambientes costeros, al contrario de los ambientes oceánicos, las asociaciones fitoplanctónicas experimentan cambios rápidos (nutrientes, luz) y en el ambiente físico (mezcla, estratificación), cambios que influencian la composición de especies (Margalef, 1978; Mann \& Lazier, 1996; Rodríguez et al., 2001). Sin embargo, en estos ambientes de condiciones fluctuantes y drásticas (e.g., magnitud y dirección de vientos, incremento/limitación de nutrientes, mayor/menor exposición a intensidad de luz, aporte de agua dulce, altas/bajas temperaturas, deficiencia de oxígeno, masas de agua), las adaptaciones fisiológicas y bioquímicas pueden llegar a ser también importantes en la estructuración de comunidades fitoplantónicas (González \& Quiñones, 2000). Al respecto, estudios enzimáticos en organismos marinos en áreas de surgencia costera han indicado la existencia de especies que presentan alta capacidad metabólica frente a condiciones de hipoxia (e.g., poliquetos: González \& Quiñones, 2000; larvas de sardina: Overnell \& Batty, 2000; Euphausia mucronata: González \& Quiñones, 2002), así como también de poblaciones pelágicas con deficiente adaptación a la condición de hipoxia (e.g., Calanus chilensis, Ulloa et al., 2001; González \& Quiñones, 2002).

En el contexto del balance de carbono en el océano, se ha utilizado la razón- $f$ entendida como la razón entre la producción nueva (basada en $\mathrm{NO}_{3}^{-}$) y la producción total $\left(\mathrm{NO}_{3}{ }^{-}+\mathrm{NH}_{4}{ }^{+}\right)($Eppley \& Peterson, 1979; Bienfang \& Ziemann, 1992). Este concepto es relevante dado que mientras un sistema funciona de forma regenerada, este no produce excedentes (todo lo que se produce se recicla). Por el contrario, en regiones de afloramiento existe una inyección continua de aguas profundas ricas en nitrato lo que determina una mayor contribución de la producción nueva y la generación de excedentes de materia orgánica (sedimentación y advección vertical). Desde una perspectiva biogeoquímica, la utilización de enzimas en conjunto con la utilización de isótopos de nitrógeno ya ha sido utilizada como una herramienta cualitativa para cuantificar la magnitud de la producción primaria proveniente ya sea de nitrato como de amonio en ambientes marinos. Específicamente, la actividad enzimática de la razón NR/GS ha sido usada como un indicador análogo a la razón-f (Rees et al., 1995; Slawyk et al., 1997; Takabayashi et al., 2005).

En el presente documento se analiza los resultados de mediciones de actividad enzimática del metabolismo intermediario del nitrógeno de ensambles fitoplanctónicos de la costa de Chile y Antártica. Mediante esta aproximación molecular, la 


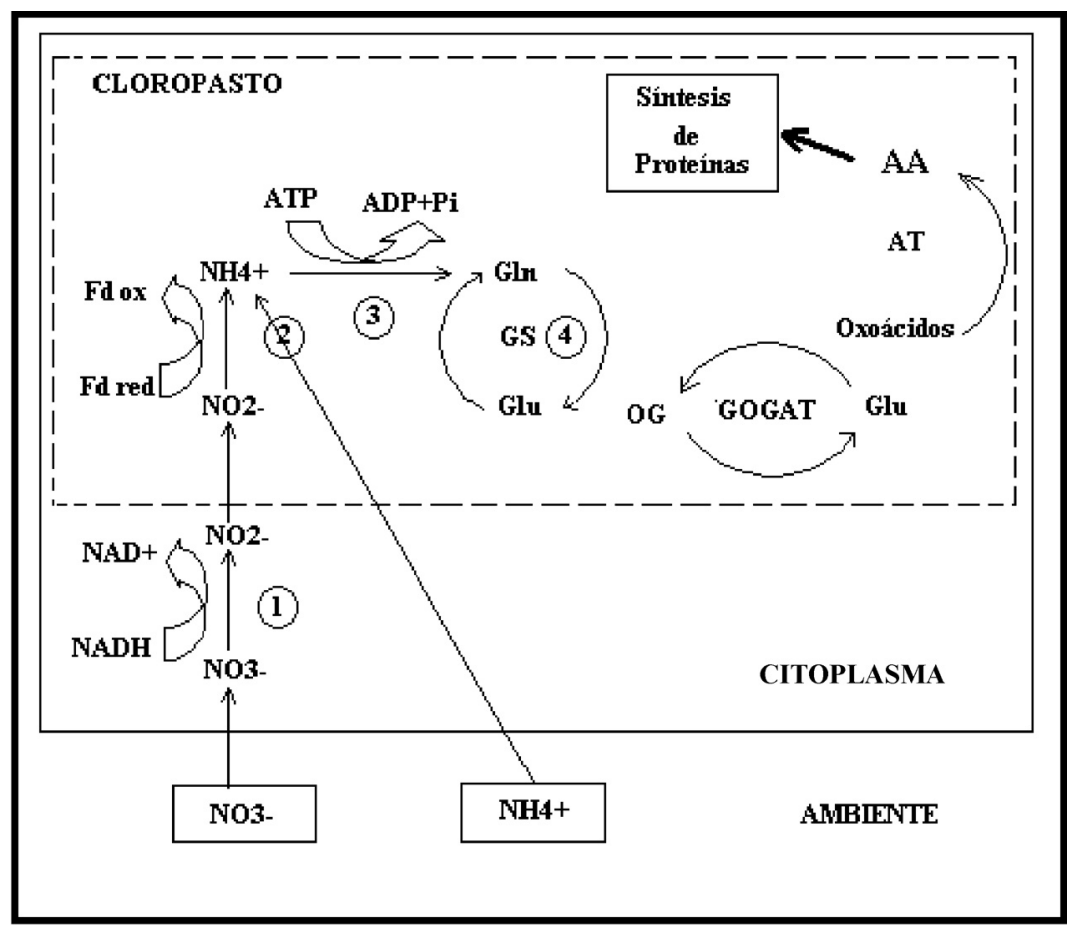

Figura 1. Reducción de $\mathrm{NO}_{3}$ y procesos metabólicos que generan amonio en los tejidos vegetales, asimilación y transporte. $\mathrm{Fd}_{\text {ox }} \mathrm{y}_{\mathrm{Fd}}$ : formas oxidada y reducida, respectivamente, de la ferredoxina, Glu: glutamato, Gln: glutamina, OG: 2-oxoglutarato, Pi: fosfato inorgánico. Enzimas: 1) nitrato reductasa, 2) nitrito reductasa, 3) glutamina sintetasa, 4) glutamato sintasa. La asimilación de nitrógeno y biosíntesis de amino-ácidos ocurre en el interior de la célula fotosintética eucariótica tanto en el citoplasma como en el cloroplasto utilizando enzimas específicas para cada compartimento. Una de las etapas de la asimilación de nitrógeno es la reducción del nitrato a amonio, que tiene lugar mediante dos reacciones consecutivas mediada por el complejo de enzimas nitrato (NR) y nitrito (NRi) reductasas (Syrett, 1981; Falkowski, 1983). En un primer paso y seguida a la incorporación de nitrato desde el medio al interior de la célula (citoplasma), la enzima nitrato reductasa reduce el nitrato a nitrito, un proceso que requiere energía en la forma de un reductor fotosintético, el NADH. En un segundo paso y en el interior del cloroplasto, el nitrito es reducido a amonio por la enzima nitrito reductasa. En el caso del amonio, una de las vías principales de asimilación, reducción y posterior incorporación a amino ácidos ocurre vía glutamina sintetasa (GS) (Syrett, 1981).

Figure 1. $\mathrm{NO}_{3}$ reduction and metabolic processes that generate ammonium in plant tissues, assimilation and transport. : $\mathrm{Fd}_{\mathrm{ox}}$ and $\mathrm{Fd}_{\mathrm{red}}$ : oxidate and reduced forms, respectively, of ferredoxin, Glu: glutamate, Gln: glutamine, $\mathrm{OG}$ : 2-oxoglutarate, Pi: inorganic phosphate. Enzymes: 1) nitrate reductase, 2) nitrite reductase, 3) glutamine synthetase, 4) glutamate synthase. Nitrogen assimilation and amino acids biosyntesis occurred at eucaryotic photosynthetic interior cells either in the cytoplasm as well as in the chloroplast using specific enzymes in each compartments. Reduction of nitrate to ammonium is mediated by the nitrate reductase complex (nitrate and nitrite reductase) by a two steps reaction that requires energy in a NADH photosynthetic reductor form (Syrett, 1981; Falkowski, 1983). In the ammonium case, one of the main assimilation, reduction and uptake into amino acids pathways, occurred via glutamine synthetase enzyme (Syrett, 1981). 
información resultante podría explicar la variabilidad de propiedades biológicas tales como actividad enzimática, biomasa y producción primaria del ensamble fitoplanctónico, en relación a la disponibilidad de nutrientes inorgánicos $\left(\mathrm{NO}_{3}^{-}, \mathrm{NH}_{4}{ }^{+}, \mathrm{PO}_{4}{ }^{\equiv}\right)$. Los estudios ecológicos in situ discutidos en este trabajo representarían las respuestas del fitoplancton tanto a nivel poblacional (desarrollo de floración algal), como de diferentes grupos funcionales u operacionales (fracciones de tamaño). El objetivo general de este estudio fue establecer si la actividad enzimática de ensambles fitoplanctónicos, como un indicador de su metabolismo interno dominante, se relaciona con la biomasa autotrófica. La constatación de estas relaciones es un paso importante para comprender el rol que juegan los procesos moleculares en la modulación de propiedades (biomasa) y procesos (producción primaria) comunitarios, especialmente en ambientes marinos con grandes fluctuaciones oceanográficas.

\section{MATERIALES Y MÉTODOS}

\section{Áreas de estudio}

Las muestras se colectaron en tres ambientes marinos: a) ambiente polar (diciembre 2000; alrededor de las islas Shetland del Sur, Antártica, $62^{\circ} \mathrm{S}$ ), b) ambiente costero-templado (marzo 2002 a septiembre 2004; seno de Reloncaví, Puerto Montt, 41³0’S) y c) ambiente subtropical de afloramiento costero (julio y octubre 2002; bahía de Mejillones, Antofagasta, $22^{\circ} \mathrm{S}$ ) (Fig. 2). El océano austral Antártico se caracteriza por su alta concentración de nutrientes y baja biomasa fitoplanctónica (High Nutrient Low Chlorophyll, HNLC), y producción primaria (High Nutrient Low Production, HNLP) (Treguer \& Jacques, 1992). Los perfiles verticales de nutrientes disueltos señalan altas concentraciones en superficie de nitrato (5-20 $\mu \mathrm{M})$, fosfato $(2-5 \mu \mathrm{M})$ y silicato $(5-25 \mu \mathrm{M})$ (Priddle et al., 1995).

El área de la península de Mejillones $\left(21^{\circ} \mathrm{S}\right)$ se localiza en el margen costero oriental del Pacífico sur. Esta área es considerada una zona de surgencia costera semipermanente, caracterizada por pulsos de altas concentraciones de nitrato $(>5 \mu \mathrm{M})$ en la zona fótica, temperatura superficial de $14-16^{\circ} \mathrm{C}$ y valores bajos de oxígeno disuelto (Rodríguez et al., 1991). La información oceanográfica del mar interior de Chiloé ha sido registrada por una serie estudios realizados durante los últimos 30 años (e.g., Pickard, 1971;
Brandhorst, 1971; Silva et al., 1995, 1997; Bastén \& Clément, 1999; Prado-Fiedler, 2000). El análisis de esta información ha mostrado la presencia de una estructura de dos capas modulada principalmente por una fuerte haloclina en los primeros $20 \mathrm{~m}$ de profundidad. Durante el período de primavera, los nutrientes presentan en los primeros $50 \mathrm{~m}$ de profundidad concentraciones de $0,4-1,2 \mu \mathrm{M}$ para el fosfato, 4-16 $\mu \mathrm{M}$ para el nitrato y $0,05-0,93 \mu \mathrm{M}$ para el amonio (Iriarte, 2005).

\section{Ensayos de actividad enzimática en fitoplancton}

Actividad enzimática para Nitrato Reductasa (NR): La actividad de este complejo enzimático fue estimada mediante una combinación de las metodologías propuestas por Eppley et al. (1969), Packard et al. (1978), Timmermans et al. (1994) y Berges \& Harrison (1995). Los filtros fueron inmersos en buffer de tolueno, para luego permeabilizar las células con tolueno y NADH, lo que provee una mezcla reductora. Los ensayos enzimáticos comenzaron con la adición de $\mathrm{KNO}_{3}$ a la mezcla y realizados a temperatura ambiente y bajo luz. Las muestras fueron tomadas a 10,20 y $30 \mathrm{~m}$ y la reacción enzimática finalizada con agua des-ionizada caliente. Posteriormente, las muestras fueron centrifugadas (15 min a $4000 \mathrm{rpm}$ ) y una alícuota del sobrenadante fue analizada en un espectrofotómetro a una longitud de $543 \mathrm{~nm}$. La actividad enzimática fue estandarizada y expresada en nmol de nitrito formado por $\mathrm{L}^{-1}$ por $\mathrm{h}^{-1}$.

Actividad enzimática para Glutamina Sintetasa (GS): las actividades de esta enzima fueron medidas en muestras de microfitoplancton, colectadas en filtros $\mathrm{GF} / \mathrm{C}$ en los distintos ambientes y almacenadas en nitrógeno líquido, por medio de un ensayo biosintético basado en la síntesis de $\gamma$-glutamil hidroxamato (Slawyk \& Rodier, 1988). Los filtros fueron suspendidos en $3 \mathrm{~mL}$ de buffer imidazol frío $(50 \mathrm{mM}, \mathrm{pH} 7,1)$ conteniendo DL-ditiotreitol (DTT $0,6 \mathrm{mM}$ ), para luego proceder con el rompimiento de células mediante un macerador de tejidos de teflónvidrio, por 1,5 min a aproximadamente $1000 \mathrm{rpm}$. Para iniciar la reacción enzimática, $1 \mathrm{~mL}$ de fluido fue usado como extracto de enzima y agregado a $0,8 \mathrm{~mL}$ de una mezcla de reacción: hidroxilamina, glutamato, ATP, $\mathrm{MgSO}_{4}$, todo mezclado con buffer de imidazol. El blanco consistió en $1 \mathrm{~mL}$ de extracto en la mezcla de reacción, el ATP ha sido reemplazado por buffer imidazol. La mezcla de ensayo fue incubada por $30 \mathrm{~min}$ a $30^{\circ} \mathrm{C}$, reacción que fue finalizada agregando una mezcla conteniendo $\mathrm{FeCl}_{3}-6 \mathrm{H}_{2} \mathrm{O}$ y 


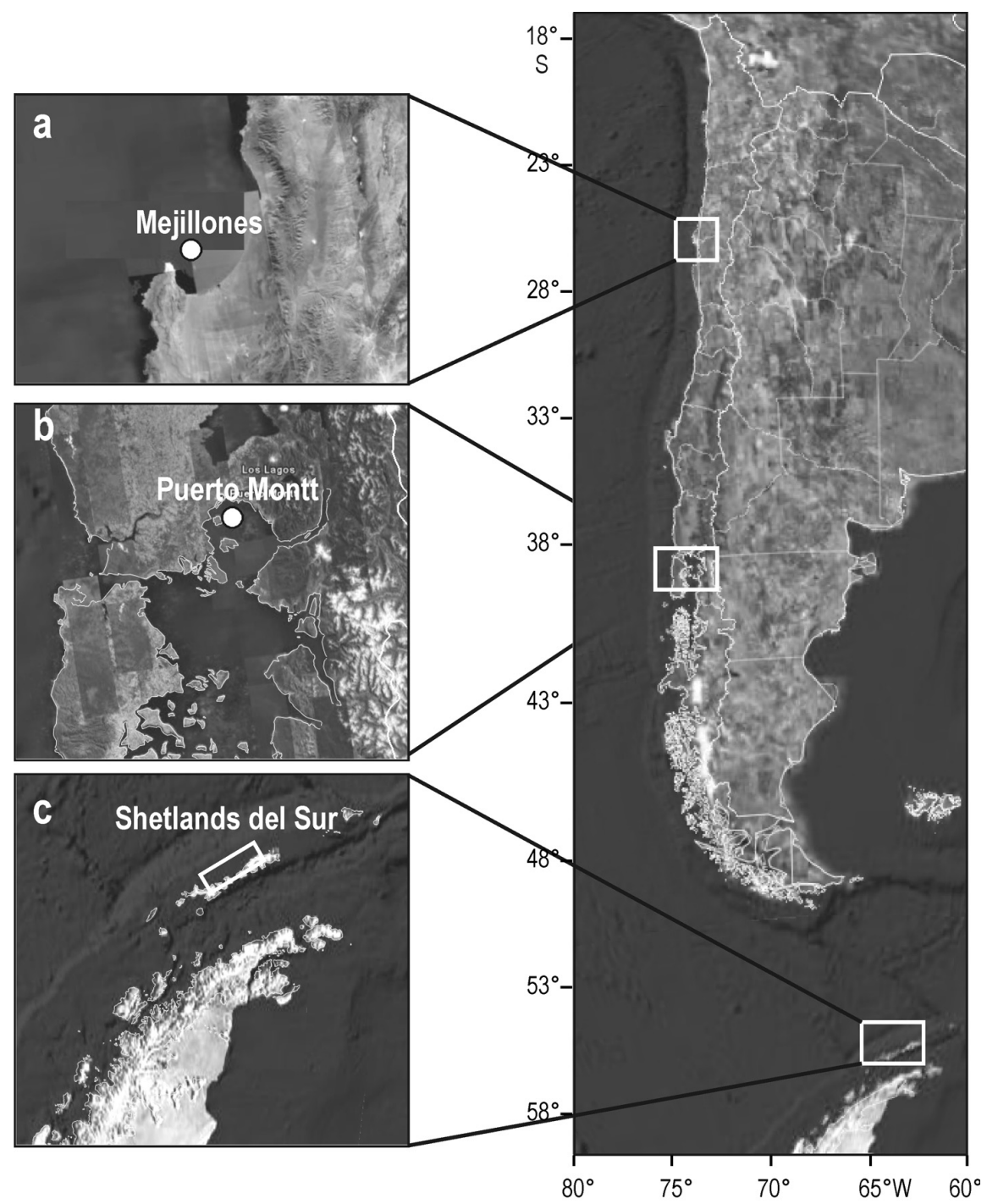

Figura 2. Áreas de estudio en la costa de Chile y Antártica, señalando los sistemas marinos muestreados para variables del fitoplancton (biomasa, actividad enzimática) y nutrientes. a) bahía de Mejillones, Antofagasta, b) seno de Reloncaví, Puerto Montt, c) islas Shetlands del Sur, Antártica.

Figure 2. Sampling areas, showing the location of the three marine systems sampled for phytoplankton variables (biomass, enzymatic activity) and nutrients. a) Mejillones Bay, Antofagasta, b) Reloncaví Fjord, Puerto Montt, c) South Shetlands Islands, Antartica.

ácido tricloroacético (TCA). Las muestras y blancos fueron centrifugados ( $10 \mathrm{~min}$ a $4000 \mathrm{rpm}$ ) y el producto final $\gamma$-glutamil hidroxamato $(\gamma$-GH) generado fue medido a una longitud de onda de $540 \mathrm{~nm}$ en un espectrofotómetro equipado con una cubeta de $1 \mathrm{~cm}$. La actividad enzimática fue expresada en términos de picomoles de $\gamma$-GH formado por célula por hora $\left(\mathrm{pmol} \mathrm{cél}{ }^{-1} \cdot \mathrm{h}^{-1}\right)$.

\section{Actividad enzimática, nutrientes y biomasa autotrófica}

Las muestras fueron colectadas mediante botellas oceanográficas Niskin $(5 \mathrm{~L})$. Se filtraron entre 2 y 5 $\mathrm{L}$ de agua de mar usando filtros $\mathrm{GF} / \mathrm{F}, 47 \mathrm{~mm}$ de fibra de vidrio, los que fueron almacenados en nitrógeno líquido para su posterior análisis enzimático. Para las áreas de seno de Reloncaví e islas Shetland del Sur, se colectaron muestras $(500 \mathrm{~mL})$ para análisis de los principales nutrientes, tales como nitrato y 
amonio, durante el período marzo 2002 a septiembre 2004 (dos muestras cada mes) y diciembre 2000, respectivamente. Para el análisis de nutrientes se filtraron las muestras en filtros $\mathrm{GF} / \mathrm{C}$ siguiendo la metodología de Parsons et al. (1984). La biomasa fue estimada indirectamente mediante la medición de clorofila "a" de acuerdo a la metodología fluorométrica recomendada por Parsons et al. (1984). Cada filtro fue almacenado en un vial con acetona a $90 \%$ y mantenido a $-30^{\circ} \mathrm{C}$ bajo oscuridad. Después de $15 \mathrm{~h}$, las muestras fueron leídas en un fluorómetro Turner Design (TD-700) previamente calibrado con clorofila pura (Sigma).

\section{Actividad enzimática y tamaño corporal en ensambles fitoplanctónicos}

Para esta actividad se caracterizó la distribución de tamaños del fitoplancton abarcando tamaños celulares entre 1 y $220 \mu \mathrm{m}$, agrupadas en siete clases de tamaño: 1-3, 5-10, 10-23, 23-53, 53-80, 80-141 у $141-220 \mu \mathrm{m}$.

Construcción de espectro de tamaños: para la relación entre la actividad enzimática y tamaño corporal del fitoplancton, se realizó la organización logarítmica de las clases de tamaño y la normalización de la actividad enzimática por clases de tamaño a la amplitud de esa clase de tamaño, de acuerdo a la metodología propuesta por Platt \& Denman (1978) $\left(\beta_{\mathrm{i}}=\mathrm{b}_{\mathrm{i}} / \Delta \mathrm{w}_{\mathrm{i}}\right)$. Para ello se obtuvo la diferencia de la actividad enzimática entre dos fracciones de tamaño, cuyo valor fue estandarizado por la marca de clase de tamaño correspondiente. Para describir ambas variables como una función continua se procedió a normalizar la variable actividad enzimática de acuerdo a la transformación propuesta por Platt \& Denman (1978): actividad enzimática normalizada $A E_{w}=A E_{i} / \Delta w_{\mathrm{i}}$ donde $A E_{i}$ es la actividad enzimática por clase de tamaño y $\Delta w_{\mathrm{i}}$ es la amplitud de la clase de tamaño $i$. Este procedimiento ha sido utilizado en los ambientes limnológico y marino (Rodríguez \& Mullin, 1986; Sprules \& Munawar, 1986). Se aplicó el modelo $\log _{2}$ (actividad enzimática normalizada, unidad $)=\log _{2} a+b \log _{2}$ (tamaño corporal, $\mu \mathrm{m}$ ), donde la variable independiente tamaño corporal $(W)$ correspondió al valor promedio del rango de tamaño $i$. Se realizó una prueba de regresión lineal simple (método de Mínimos Cuadrados, Zar, 1984) para detectar relación significativa entre las variables dependientes normalizada por tamaño corporal (actividad enzimática y producción primaria) y la variable independiente (tamaño corporal).

\section{RESULTADOS}

\section{Actividad enzimática distribuida por tamaño corporal}

La actividad de la nitrato reductasa $\left(b_{\mathrm{S} \text { Reloncaví }}=\right.$ 0,$\left.93 ; b_{\mathrm{B} \text { Mejillones }}=-0,65\right)$ y de la glutamina sintetasa $\left(b_{\mathrm{S} \text { Reloncaví }}=-0,79\right)$ disminuyeron con el aumento del tamaño corporal del ensamble fitoplanctónico (Fig. 3). Las pendientes menores a $-1,0$, señalan la importancia relativa de los ensambles fitoplanctónicos dominados por diatomeas en aguas costeras ricas en nutrientes. En este estudio se obtiene que la actividad enzimática de la nitrato reductasa y la glutamina sintetasa distribuida por tamaño del fitoplancton en el rango 2-200 $\mu \mathrm{m}$ puede ser representada por una relación linear inversa significativa, en dos áreas marinas costeras (seno de Reloncaví y bahía de Mejillones).

\section{Relación entre actividad enzimática y biomasa autotrófica}

Durante la floración algal del dinoflagelado Gymnodinium chlorophorum, en la región sur-austral de Chile $\left(41^{\circ} 30^{\prime}-43^{\circ} \mathrm{S}\right)$ se observó un aumento en la actividad de glutamina sintetasa y de manera inversa, una disminución de la actividad enzimática de la nitrato reductasa durante el período de máxima abundancia $\left(15.000\right.$ cél $\left.\cdot \mathrm{ml}^{-1}\right)$ y de biomasa de esta especie. Previo al período de la floración los valores promedio de actividad NR registrados fueron de $134,7 \mathrm{nmol} \mathrm{h}^{-1} \cdot \mathrm{L}^{-1}$ (rango: $46,42-227,82 \mathrm{nmol} \mathrm{h}^{-1} \cdot \mathrm{L}^{-1}$ ), y para la actividad promedio de GS fue de $43,17 \mathrm{nmol} \mathrm{GH} \mathrm{h}{ }^{-1} \cdot \mathrm{L}^{-1}$ (rango: 7-107,39 $\mathrm{nmol} \mathrm{h}^{-1} \cdot \mathrm{L}^{-1}$ ). Durante la floración, la actividad de NR disminuye a un promedio de 5,75 nmol h${ }^{-1} \cdot \mathrm{L}^{-1}$ (rango: 2,34-14,34 $\mathrm{nmol} \mathrm{h}^{-1} \cdot \mathrm{L}^{-1}$ ) y aumenta la actividad promedio de la glutamina sintetasa a $1.230,9 \mathrm{nmol} \mathrm{GH} \mathrm{h}{ }^{-1} \cdot \mathrm{L}^{-1}$ (rango: 321,95-2.498,05 $\left.\mathrm{nmol} \mathrm{GH} \mathrm{h} \mathrm{h}^{-1} \cdot \mathrm{L}^{-1}\right)$. Un resultado interesante fue la disminución de la relación NR/GS durante la floración algal en condiciones de concentraciones limitantes de nutrientes disueltos de origen nitrogenado $(<1 \mu \mathrm{M}$ de $\mathrm{NO}_{3}^{-} \mathrm{y} \mathrm{NH}_{4}^{+}$).

Durante el período de elevada actividad de glutamina sintetasa (GS), el ensamble fitoplanctónico fue dominado por Gymnodinium chlorophorum. La baja actividad de la NR corresponde a la elevada concentración de clorofila $a$ y la actividad de la GS evidencia que ciertas especies de dinoflagelados prefieran las formas de nitrógeno reducido (amonio y urea) en comparación a nitrato o nitrito. La relación positiva 

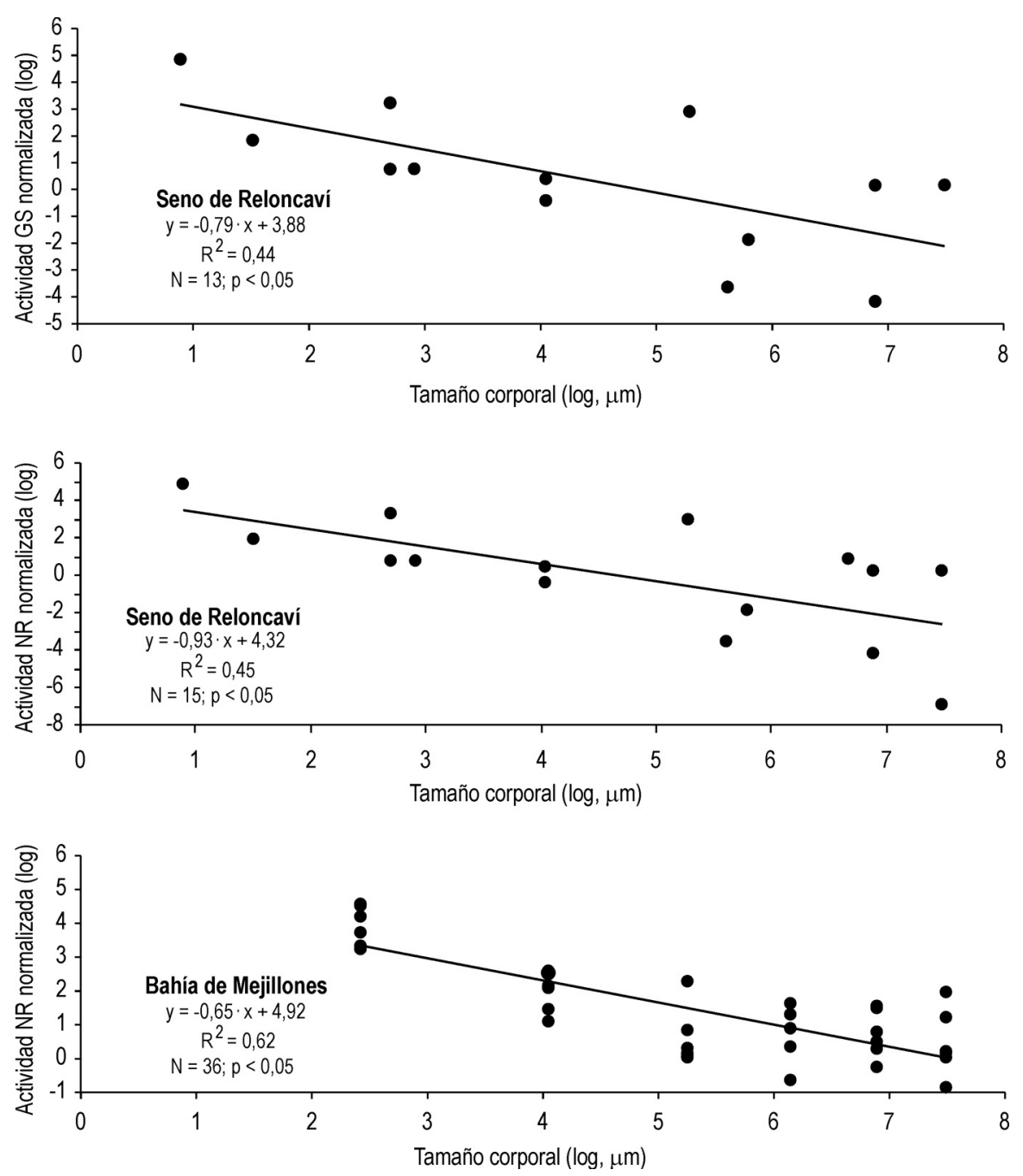

Figura 3. Actividad enzimática de nitrato reductasa y glutamina sintetasa distribuida por clase de tamaño de ensambles de fitoplancton en bahía de Mejillones $\left(23^{\circ} \mathrm{S}\right)$ y seno de Reloncaví $\left(41^{\circ} \mathrm{S}\right)$.

Figure 3. Enzymatic activity of nitrate reductase and glutamine synthetase size-distributed of phytoplankton assemblages at Mejillones Bay $\left(2^{\circ} \mathrm{S}\right)$ and Reloncavi Fjord $\left(41^{\circ} \mathrm{S}\right)$.

entre la actividad de GS y clorofila $a\left(\mathrm{r}^{2}=0,76 ; \mathrm{p}<\right.$ $0,05)$ durante el período de la floración puede tener implicancias para la ecofisiología del fitoplancton. La GS participa en la asimilación del $\mathrm{NO}_{3}^{-}$, como un indicador en la asimilación de $\mathrm{NO}_{3}^{-}, \mathrm{NH}_{4}^{+}$y urea. En la fase de crecimiento de la floración de $G$. chlorophorum en el seno de Reloncaví, el aumento en biomasa (como clorofila $a$ ) del dinoflagelado estuvo relacionado de manera linear a la actividad de GS, para posteriormente permanecer constante a altas concentraciones de biomasa (Fig. 4). El análisis por área de estudio de las actividades enzimáticas señala las diferentes magnitudes observadas entre regiones en la relación entre la biomasa fitoplanctónica y la actividad enzimática de nitrato reductasa (Fig. 5).

\section{Rol biogeoquímico de la actividad enzimática}

La razón de incorporación de nitrato con respecto a la de nitrógeno inorgánico total $\left(\mathrm{\rho NO}_{3}^{-} /\left(\mathrm{\rho NO}_{3}{ }^{-}+\right.\right.$ $\left.\rho \mathrm{NH}_{4}^{+}\right)$), conocida como razón- $f$ (Eppley \& Peterson, 1979), ha sido usada como un indicador de la relativa contribución de la producción nueva $\left(\mathrm{\rho NO}_{3}^{-}\right)$y la producción regenerada $\left(\mathrm{\rho NH}_{4}^{+}\right)$a la producción total. Dado que las actividades totales de nitrato reductasa reflejan solamente el crecimiento usando nitrato (ca- 


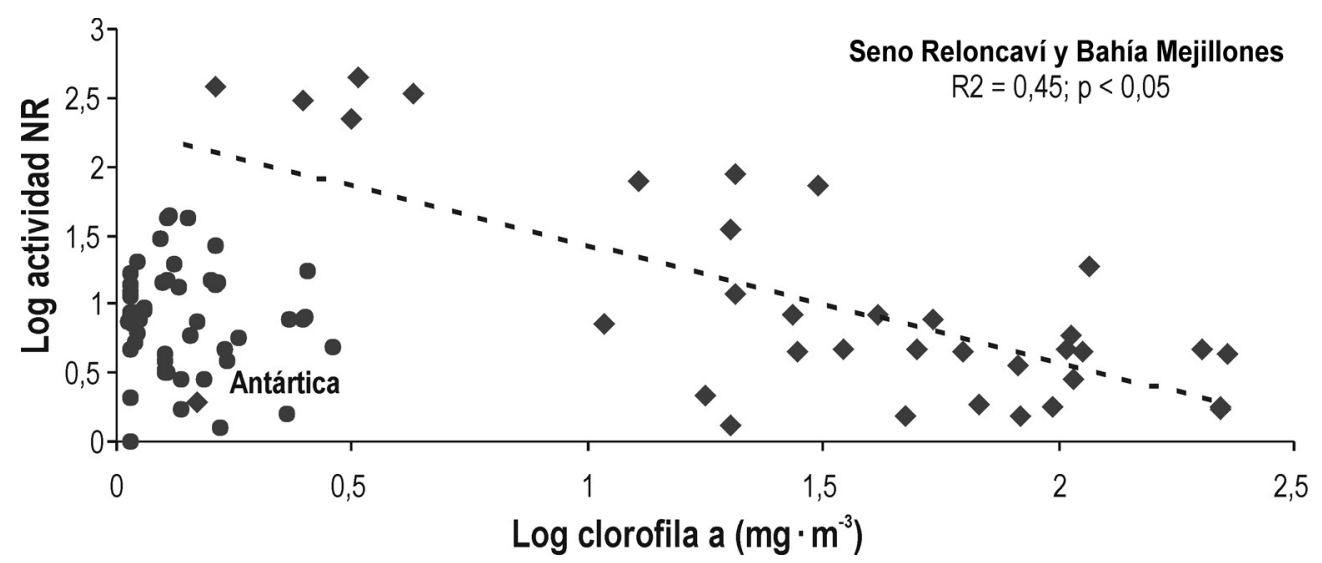

Figura 4. Relación (log-log) entre la actividad de nitrato reductasa $\left(\mathbf{n m o l ~ h} \mathbf{h}^{-1} \cdot \mathbf{L}^{-1}\right)$ y biomasa (como clorofila $\left.a\right)$ en ensambles fitoplanctónicos de la Antártica (primavera: diciembre 2000), seno de Reloncaví (verano-otoño 2003) y bahía de Mejillones (octubre 2002, enero 2003).

Figure 4. Relationship (log-log) between the activity of nitrate reductase $\left(\mathrm{nmol} \mathrm{h}^{-1} \cdot \mathbf{L}^{-1}\right)$ and biomass (as chlorophyll a) of phytoplankton assemblages in Antarctica (austral spring: December 2000), Reloncavi Fjord (summer-fall 2003) and Mejillones Bay (October 2002 and January 2003).

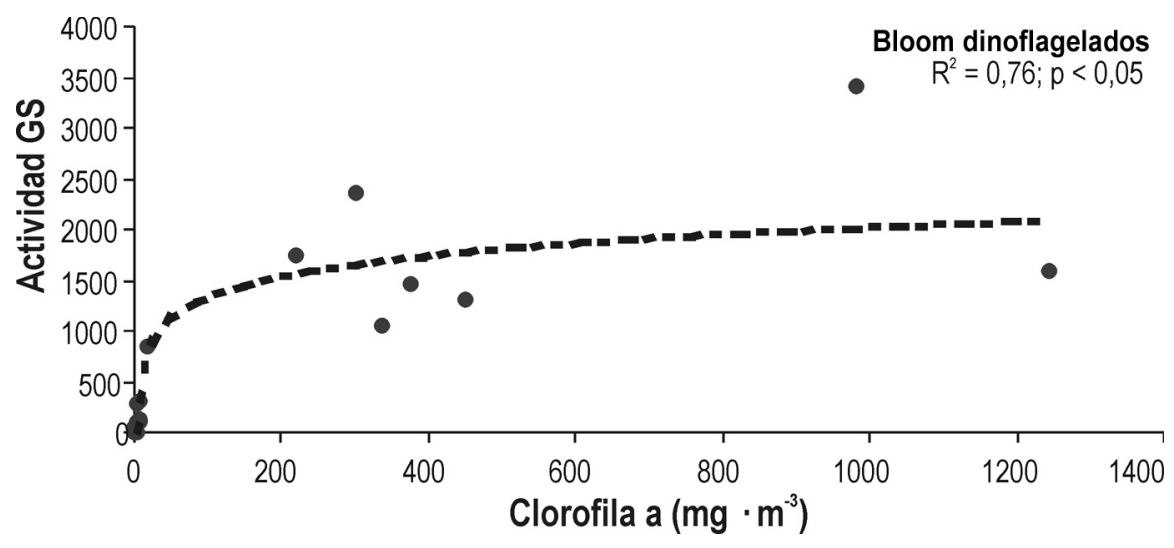

Figura 5. Relación no lineal cuadrática entre la actividad de glutamina sintetasa $\left(\mathrm{nmol}^{\mathbf{2}} \cdot \mathrm{L}^{-1}\right)$ y biomasa (como clorofila $a$ ) durante el seguimiento de la floración de una especie de dinoflagelado (Gymnodinium chlorophorum) observado en el seno de Reloncaví $\left(41^{\circ} 30^{\circ} \mathrm{S}\right)$ durante marzo-abril 2003.

Figure 5. Non-lineal relationship between activity of glutamine synthetase $\left(\mathbf{n m o l ~ h} \mathbf{h}^{-1} \cdot \mathbf{L}^{-1}\right)$ and biomass (as chlorophyll $a$ ) during a short time series of a dinoflagellate bloom (Gymnodinium chlorophorum) at Reloncavi Fjord (41³0'S) observed in March-April 2003.

talizan reacciones desde $\mathrm{NO}_{3}{ }^{-}$del ambiente Eppley et al. (1969) y glutamina sintetasa refleja la utilización de nitrato y amonio (catalizan reacciones desde $\mathrm{NH}_{4}^{+}$ del ambiente y desde la reducción de nitrato y nitrito; Bressler \& Ahmed, 1984), ellas pueden ser usadas como indicadores cualitativos análogos a la razón- $f$ en sistemas costeros y oceánicos. Los datos señalan que una significativa proporción de las muestras se encuentra cercana a una razón- $f$ de actividad enzimática entre 0,5 y 1 (Fig. 6), correspondientes a ambientes costeros en los cuales dominan el grupo de las diatomeas. Sin embargo, durante la floración algal de un dinoflagelado, donde la actividad de NR es 0 , la razón- $f$ de actividad enzimática fue menor que 0,5 . 


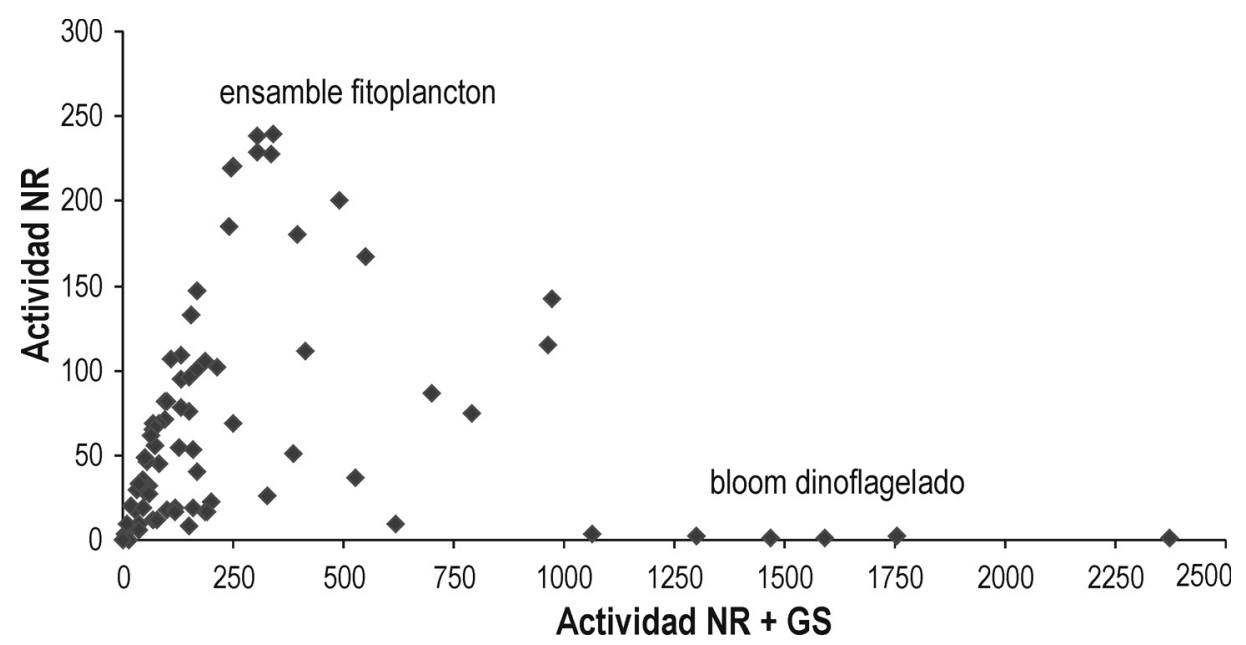

Figura 6. Relación entre la actividad de nitrato reductasa $\left(\mathrm{nmol} \mathrm{h}^{-1} \cdot \mathrm{L}^{-1}\right)$ y la sumatoria de actividades enzimáticas de nitrato reductasa y glutamina sintetasa $\left(\mathrm{nmol} \mathrm{h}^{-1} \cdot \mathrm{L}^{-1}\right)$ para muestras del seno de Reloncaví $\left(41^{\circ} 30^{\prime} S\right)$ y bahía de Mejillones $\left(23^{\circ} \mathrm{S}\right)$.

Figure 6. Relationship between activity of nitrate reductase $\left(\mathrm{nmol} \mathrm{h}^{-1} \cdot \mathbf{L}^{-1}\right)$ and glutamine synthetase plus nitrate reductase $\left(\mathrm{nmol} \mathrm{h}^{-1} \cdot \mathrm{L}^{-1}\right)$ at Reloncavi Fjord $\left(41^{\circ} 30^{\prime} \mathrm{S}\right)$ and Mejillones Bay $\left(23^{\circ} \mathrm{S}\right)$.

\section{DISCUSIÓN}

La aproximación enzimática tamaño-dependiente intenta describir la existencia de una regularidad a nivel celular considerando distintos grupos funcionales (nanoflagelados, diatomeas, dinoflagelados). Los análisis realizados en sistemas oligotróficos en estado estable y considerando una amplia escala de tamaños (desde bacterias hasta zooplanctéres), han mostrado una linearidad en el espectro de biomasa (como carbono) normalizado por tamaño (Rodríguez \& Mullin, 1986; Quiñones et al., 2003). La regularidad del espectro de biomasa en ambientes oligotróficos sugiere que tanto los procesos metabólicos así como también de organización trófica son importantes fuerzas que la estructuran (Fry \& Quiñones, 1994; Quiñones et al., 2003; Cermeño et al., 2005).

Aunque los resultados presentados en este estudio indican una linearidad en la actividad enzimática distribuida por tamaños del fitoplancton, las pendientes son significativamente distintas al valor de $-1,0$ propuesto por Platt \& Denman (1978). Esta desviación puede ser debida a las estrategias de vida de los diferentes grupos fitoplanctónicos presentes en ambientes costeros altamente heterogéneos espacial y temporalmente, como factores que modulan la biomasa y producción primaria (nutrientes, luz, depredación). De acuerdo a la visión clásica, en ambientes costeros de surgencia (semipermanente) existe un predominio de especies fitoplanctónicas de gran tamaño (Mann \& Lazier, 1996), que en comparación con las poblaciones del nano y picoplancton, tendrían una mayor ventaja competitiva en la cinemática de incorporación de nutrientes llevados a la superficie (Malone, 1980). Además, cambios en el espectro de biomasa podrían ser el resultado de la variabilidad estacional esperada en ambientes costeros templados (Witek \& Krajewska-Soltys, 1987; Rodríguez et al., 2001), como resultado principalmente de cambios estacional de la irradianza y nutrientes o debido al efecto de eventos remotos tales como El Niño sobre los ensambles de fitoplancton (Iriarte \& González, 2004). Al respecto, la distribución por tamaños de partículas autotróficas en los ambientes marinos podría ser una función de la disponibilidad, magnitud y estado químico de los nutrientes en la capa fótica; un incremento en producción primaria basada en advección vertical de nutrientes $\left(\mathrm{NO}_{3}\right.$, producción nueva) resultaría en una mayor biomasa del microfitoplancton (pendiente menos negativa). En contraste, las áreas de producción regenerada $\left(\mathrm{NH}_{4}\right.$, remineralización activa en la capa eufótica), se caracterizarían por una relativa alta biomasa del componente del picoplancton.

El incremento en la biomasa del fitoplancton y en la actividad de GS, con concentraciones de nutrientes inorgánicos bajos y constantes, puede implicar que la GS es un indicador de la utilización de nitrógeno 
orgánico disuelto por parte de esta especie de dinoflagelado (Gymnodinium chlorophorum). La ocurrencia de especies FAN (Floraciones Algales Nocivas) y especialmente de dinoflagelados ha sido relacionado con altas y/o frecuentes adiciones de $\mathrm{NH}_{4}{ }^{+} \mathrm{O}$ nitrógeno orgánico disuelto (e.g., urea) (Wilkerson \& Grunseich, 1990; Glibert \& Terlizzi, 1999; Berg et al., 2002; Dyhrman \& Anderson, 2003). Sin embargo, poco se sabe sobre la expresión de diferentes actividades enzimáticas y de respuestas ecofisiológicas relacionadas con las especies responsables de la formación de FAN bajo las diferentes fuentes de nitrógeno.

Existe evidencia experimental en poblaciones de microalgas con deficiencia en nitrógeno (concentraciones ambientales bajas) que poseen una actividad más alta de GS que las que crecen en altos niveles de nitrato (Chaetoceros affinis, Slawyk \& Rodier, 1986), (Phaeodactylum tricornutum, Slawyk \& Rodier, 1988). Diversos estudios han demostrado que la contribución relativa de los flujos de nitrógeno orgánico disuelto versus el nitrógeno inorgánico disuelto pueden alterar perceptiblemente la composición del ensamble, la biomasa y la productividad primaria (Dyhrman \& Anderson, 2003). La dinámica de nutrientes inorgánicos disueltos en superficie en el seno de Reloncaví señala una gran variabilidad estacional, con concentraciones máximas de nitrato y ortofosfato en invierno $\left(\mathrm{NO}_{3}{ }^{-}=30 \mu \mathrm{M} ; \mathrm{PO}_{4}{ }^{\equiv}=2,4\right.$ $\mu \mathrm{M})$ y concentraciones mínimas en verano tardío $\left(\mathrm{NO}_{3} \equiv=0,1 \mu \mathrm{M} ; \mathrm{PO}_{4}^{-}=0,3 \mu \mathrm{M}\right)$. Las concentraciones de amonio no mostraron una variabilidad temporal significativa durante otoño e invierno, cuyos valores promedios fluctuaron entre $1,4 \mu \mathrm{M}$ y $1,3 \mu \mathrm{M}$, respectivamente. La información disponible de nutrientes inorgánicos en esta región revela una razón baja de $\mathrm{NO}_{3} \equiv: \mathrm{PO}_{4}{ }^{-} \approx 7$, lo cual sugiere que el ensamble fitoplanctónico podría agotar el nitrato de la columna de agua antes que el ortofosfato. Por lo tanto la fisiología del nitrógeno puede ser importante para la dinámica de G. chlorophorum y quizás de otras FAN en aguas costeras meridionales de Chile. La baja concentración de nitrato en la columna de agua se puede explicar por la incorporación del fitoplancton $y / o$ por una mezcla de bajos contenidos de nutrientes agregados por el agua dulce (desde ríos y precipitaciones), como se ha registrado en el margen de Chile meridional. Las concentraciones máximas de nitrato registradas en el área costera del seno de Reloncaví $(30 \mu \mathrm{M})$ podrían estar afectadas por la adición de nitrógeno desde fuentes antrópicas adyacentes al sistema marino costero, en contraste con los menores rangos de concentraciones en los sistemas de canales y fiordos del sur de Chile (Silva et al., 1997; Prado-Fiedler, 2000).

Al comparar las áreas de estudio y observar valores distintivos de actividad enzimática, sugiere que la actividad de NR en organismos autotróficos es altamente influenciada por factores ambientales tales como el origen de nitrógeno, luz y temperatura (Berges \& Harrison, 1995; Lomas, 2004). En la región Antártica, considerado un ambiente alto en nutrientes y baja biomasa (HNLC), no se observa un patrón determinado, indicando valores bajos de biomasa autotrófica relacionados a baja actividad de NR. Varios estudios realizados en el océano austral han dado posibles explicaciones para esta paradoja a través de diversas hipótesis, entre ellas la estabilidad de la columna de agua, limitación debida a la luz (Nelson \& Smith, 1991), alta presión de herbivoría (Frost \& Franzen, 1992), limitación de macronutrientes (Holm-Hansen et al., 1994) y limitación por Fe sobre la producción primaria (Helbling et al., 1991). Nuestra observación puede ser el resultado de la dominancia de nanoflagelados autotróficos, baja concentración de Fe (elemento esencial para la catálisis del complejo enzimático de nitrato reductasas), y temperaturas cercanas a $0^{\circ} \mathrm{C}$. Por el contrario, en ambientes costeros templados (seno de Reloncaví y bahía de Mejillones), donde dominan las diatomeas, se observa una relación inversa, es decir la actividad enzimática de NR disminuye en ensambles fitoplanctónicos con alta biomasa autotrófica. Finalmente, las desviaciones de una relación directa esperable entre actividad enzimática y biomasa autotrófica (e.g., células nuevas), puede ser explicada considerando la influencia de factores intrínsecos tales como la interacción entre actividad enzimática y diferentes sustratos nitrogenados (e.g., represión de NR por amonio (Vergara et al., 1998; Lomas, 2004)), la identidad del grupo funcional fitoplanctónico (Lomas et al., 1996; Glibert \& Terlizzi, 1999)), el estado nutricional interno de las células (presencia de vacuolas (Collos et al., 2004)), y potencialmente si las células se encuentran en crecimiento vegetativo o en dormancia, o en el estado final de células senescentes.

A través de una aproximación enzimática, razones de $f$ entre 0,5 y 1 y $<0,5$ sugiere la contribución de las diatomeas a la producción nueva (basada en nitrato) en comparación a los flagelados, los cuales contribuyen significativamente a la producción regenerada (basada en amonio), respectivamente. Un siguiente paso en esta dirección, sería evaluar si las mediciones moleculares de la razón- $f$ son comparables 
a las mediciones biogeoquímicas de incorporación de carbono $\left({ }^{14} \mathrm{C}\right)$ y nitrógeno $\left({ }^{15} \mathrm{~N}\right)$ en ensambles fitoplanctónicos de distintos ambientes marinos. Finalmente, el rol que juega tanto la deficiencia o la adición de nutrientes en el incremento o disminución de las actividades enzimáticas estudiadas (GS, NR), permite utilizarlas en estudios in situ como indicador del estado nutritivo del fitoplancton, y por lo tanto de cambios en la biomasa autotrófica y la producción primaria. El material orgánico formado está activamente involucrado en el ciclo biogeoquímico de acuerdo al modelo conceptual propuesto (Fig. 7): el material es originado desde la reducción y conversión de nutrientes inorgánicos a compuestos orgánicos que estructuran el metabolismo celular del fitoplancton (en términos de carbono, nitrógeno y fósforo) y que promueve el crecimiento de los componentes de la trama trófica desde bacterias (bacterias, material orgánico disuelto, excreción de organismos) a or- ganismos micro-mesozooplanctónicos (herbivoría, material orgánico particulado).

\section{AGRADECIMIENTOS}

Esta investigación fue financiada por el proyecto “Apoyo Beca de Doctorado 2002-2004" otorgado por el Fondo Nacional de Desarrollo Científico y Tecnológico CONICYT-FONDECYT-Chile. Financiamiento adicional fue otorgado por proyectos FONDECYT No 5960002-1996, 1000419-2000, 150100007-2002, así como también a FONDAPCOPAS-UdeC (FONDECYT-CONICYT). Finalmente, se agradece el financiamiento otorgado por el Instituto de Investigación Oceánica y Desarrollo (KORDI-Corea) a través de los programas Antártico No PP02102 y PP02104 y el apoyo de la Dirección de Investigación y Desarrollo de la Universidad Austral de Chile.

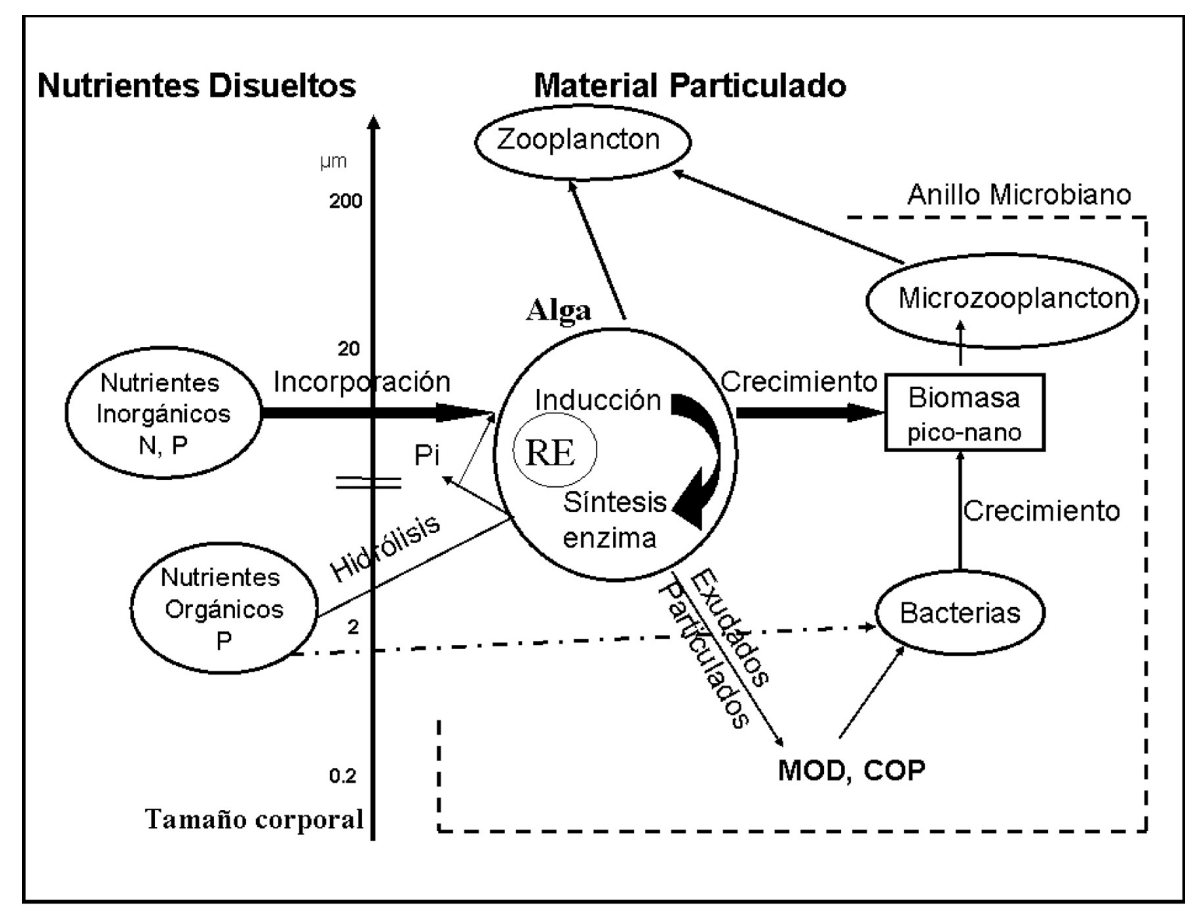

Figura 7. Representación esquemática de una trama trófica del sistema marino, adicionando procesos de incorporación de nutrientes inorgánicos disueltos y transformación a materia orgánica particulada (MOP) vía reacciones metabólicas enzimáticas (RE) de los productores primarios. Esta conversión a materia orgánica gatilla el funcionamiento y la estructuración de la trama trófica, desde los componentes del anillo microbiano a los grupos consumidores del mesozooplancton.

Figure 7. Conceptual model showing a marine food web, including processes such as uptake of dissolved inorganic nutrients and transformation to particulate organic matter (POM) via enzymatic reactions (ER) of primary producers. The transformation to organic matter triggered the functioning and structure of the trophic web from microbial food web components to larger mesozooplankton consumer groups. 


\section{REFERENCIAS}

Bastén, J. \& A. Clement. 1999. Oceanografía del estuario de Reloncaví, X Región de Chile. Cien. Tecnol. Mar, 22: 31-46.

Berg, G.M., D.J. Repeta \& J. Laroche. 2002. Dissolved organic nitrogen hydrolysis rates in axennic cultures of Aureococcus anophagefferens (Pelagophyceae): comparison with heterotrophic bacteria. Applied Environ. Microbiol., 68: 401404.

Berges, J. \& P.J. Harrison. 1995. Nitrate reductase activity quantitatively predicts the rate of nitrate incorporation under steady state light limitation: a revised assay and characterization of the enzyme in three species of marine phytoplankton. Limnol. Oceanogr., 40: 82-93.

Bienfang, P.K. \& D.A. Zieman. 1992. The role of coastal high latitude ecosystems in global export production. En: P.G. Falkowski \& A.D. Woodhead (eds.). Primary productivity and biogeochemical cycles in the sea. Plenum Press. New York, 285298 pp.

Blasco, D. \& H.L. Conway. 1982. Effect of ammonium on the regulation of nitrate assimilation in natural phytoplankton populations. J. Exp. Mar. Biol. Ecol., 61: 157-168.

Blasco, D., J.J. Macisaac, T.T. Packard \& R.C. Dugdale. 1984. Relationship between nitrate reductasa and nitrite uptake in phytoplankton in the Peru upwelling region. Limnol. Oceanogr., 29: 275-286.

Brandhorst W. 1971. Condiciones oceanográficas estivales frente a la costa de Chile. Rev. Biol. Mar., Valparaíso, 14: 45-84.

Bressler, S.L. \& S.I. Ahmed. 1984. Detection of glutamine synthetase activity in marine phytoplankton: optimization of the biosynthetic assay. Mar. Ecol. Prog. Ser., 14: 207-217.

Cermeño, P., E. Marañón, J. Rodríguez \& E. Fernández. 2005. Size dependence of coastal phytoplankton photosynthesis under vertical mixing conditions. J. Plankton Res., 27: 473-483.

Collos, Y. \& J. Lewin. 1974. Blooms of surf-zone diatoms along the coast of the Olympic Peninsula, Washington. 5. Nitrate reductase activity in natural populations and laboratory cultures of Chaetoceros armatum and Asterionella socialis. Mar. Biol., 25: 213-221.

Collos, Y. \& G. Slawyk. 1976. Significance of celular nitrate content in natural populations of marine populations growing in shipboard cultures. Mar. Biol., 34: 27-32.
Collos, Y., C. Gagne, M. Laabir, A. Vaquer, P. Cecchi. \& P. Souchu. 2004. Nitrogenous nutrition of Alexandrium catenella (Dinophyceae) in cultures and in Thau Lagoon, Southern France. J. Phycol., 40: 96-103.

Dunne, J.P., J.W. Murray. \& A.K. Aufdenkampe. 1999. Silicon-nitrogen coupling in the equatorial Pacific upwelling zone. Global Biogeoch. Cycles, 13: 715-726.

Dyhrman, S.T. \& D.M. Anderson. 2003. Urease activity in cultures and field populations of the toxic dinoflagellate Alexandrium. Limnol. Oceanogr., 48: 647-655.

Eppley, R.W., J.L. Coatsworth. \& L. Solorzano. 1969. Studies of nitrate reductase in marine phytoplankton. Limnol. Oceanogr., 14: 194-205.

Eppley, R.W. \& B.J. Peterson. 1979. Particulate organic matter flux and planktonic new production in the deep ocean. Nature, 282: 677-680.

Falkowski, P.G. 1983. Enzymology of nitrogen assimilation. En: E.J. Carpenter \& D.G. Capone (eds.). Nitrogen in the marine environment. Academic Press, New York, pp. 839-868.

Flynn, K.J. \& C.R. Ripkin. 1999. Interactions between iron, light, ammonium, and nitrate: insights from the construction of a dynamic model of algal physiology. J. Phycol., 35: 1171-1190.

Frost, B.W.E. \& N.C. Franzen. 1992. Grazing and iron limitation in the control of phytoplankton stock and nutrient concentration: a chemostat analogue of the Pacific equatorial upwelling zone. Mar. Ecol. Progr. Ser., 83: 291-303.

Fry, B. \& R.B. Quiñones. 1994. Biomass spectra and stable isotope indicators of trophic level in zooplankton of the northwest Atlantic. Mar. Ecol. Progr. Ser., 112: 201-204.

Geider, R.J., J. La Roche, R.M. Greene \& M. Olaizola. 1993. Responses of the photosynthetic apparatus of Phaeodactylum tricornutum (Bacillariophyceae) to nitrate, phosphate, or iron starvation. J. Phycol., 29: 755-766.

Glibert, P.M. \& D.E. Terlizzi. 1999. Cooccurrence of elevated urea levels and diniflagellate blooms in temperate estuarine aquaculture ponds. Appl. Environ. Microbiol., 65: 5594-5596.

González, R.R. \& R.A. Quiñones. 2000. Pyruvate oxidoreductases involved in glycolytic anaerobic metabolism of polychaetes from the continental shelf off central-south Chile. Estuar. Coast. Shelf Sci., 51: 507-519.

González, R.R. \& R.A. Quiñones. 2002. Ldh activity in Euphausia mucronata and Calanus chilensis: 
implications for vertical migration behaviour. J. Plankton Res., 24: 1349-1356.

Greene, R.M., R.J. Geider \& P.G. Falkowski. 1991. Effect of iron limitation on photosynthesis in a marine diatom. Limnol. Oceanogr., 36: 17721782.

Helbling, E.W., V. Villafañe \& O. Holm-Hansen. 1991. Effect of $\mathrm{Fe}$ on productivity and size distribution of Antarctic phytoplankton. Limnol. Oceanogr., 36: 1879-1885.

Herbland, A., D. Delmas, P. Laborde, B. Sautour \& F. Artigas. 1998. Phytoplankton spring bloom of the Gironde plume waters in the Bay of Biscay: early phosphorus limitation and food-web consequences. Oceanol. Acta, 21: 279-291.

Holm-Hansen, O, A. Amos, N. Silva, V. Villafañe \& E.W. Helbling. 1994. In situ evidence for a nutrient limitation of phytoplankton growth in pelagic Antarctic waters. Antar. Sci., 6: 315-324.

Hutchins, D.A. \& K.W. Bruland. 1998. Iron-limited diatom growth and $\mathrm{Si}: \mathrm{N}$ uptake ratios in a coastal upwelling regime. Nature, 393: 561-564.

Iriarte, J.L. \& H.E. González. 2004. Phytoplankton size structure during and alter the 1997/98 El Niño in a coastal upwelling area of the northern Humboldt Current System. Mar. Ecol. Progr. Ser., 269: 83-90.

Iriarte, J.L., R. Quiñones \& R.R. González. 2005. Relationship between biomass and enzymatic activity of a bloom-forming dinoflagellate (Dinophyceae) in Southern Chile $\left(41^{\circ} \mathrm{S}\right)$ : a field approach. J. Plankton Res., 27: 159-166.

Iriarte, J.L. 2005. Relación entre actividad enzimática y biomasa de ensambles fitoplanctónicos en el sistema pelágico. Tesis de Doctorado, Escuela de Graduados, Universidad de Concepción, Concepción, Chile, 74 pp.

Liebig, J. 1843. Chemistry in its applications to agriculture and physiology. Taylor \& Walton, London, $400 \mathrm{pp}$.

Lomas, M.W., P.M. Glibert \& G.M. Berg. 1996. Characterization of nitrogen uptake by natural populations of Aureococcus anophagefferens (Chrysophyceae) as a function of incubation duration, substrate concentration, light, and temperature. J. Phycol., 32: 907-916.

Lomas, M.W. \& P.M. Glibert. 2000. Comparisons of nitrate uptake, storage, and reduction in marine diatoms and flagellates. J. Phycol., 36: 903-913.

Lomas, M.W. 2004. Nitrate reductase and urease enzyme activity in the marine diatom Thalassiosira weissflogii (Bacillariophyceae): interactions among nitrogen substrates. Mar. Biol., 144: 37-44.

Mann, K.H. \& J.R.N. Lazier. 1996. Dynamics of marine ecosystems: biological-physical interactions in the oceans. Blackwell Science, Oxford, $394 \mathrm{pp}$.

Malone, T.C. 1980. Algal size. En: I. Morris (ed.). The physiological ecology of phytoplankton. Blackwell, Oxford, pp. 433-463.

Margalef, R. 1978. Life-forms of phytoplankton as survival alternatives in an instable environment. Oceanol. Acta, 1: 493-509.

Nelson, D.M. \& W.O. Smith. 1991. Sverdrup revisited: critical depths, maximum chlorophyll levels, and the control of southern Ocean productivity in the irradiance-mixing regime. Limnol. Oceanogr., 36: 1650-1661.

Overnell, J. \& R.S. Batty. 2000. Scaling of enzyme activity in larval herring and plaice: effects of temperature and individual growth rate on aerobic capacity. J. Fish. Biol., 56: 577-589.

Packard, T.T., R.C. Dugdale, J.J. Goering \& R.T. Barber. 1978. Nitrate reductase activity in the subsurface waters of the Peru current. J. Mar. Res., 36: 59-76.

Parsons, T.R., Y. Maita \& C.M. Lalli. 1984. A manual of chemical and biological methods for seawater analysis. Pergamon Press, Oxford, 173 pp.

Pickard, G. 1971. Some physical oceanographic features of inlets of Chile. J. Fish. Board Can., 28: 1077-1106.

Platt, T. \& K. Denman. 1978. The structure of pelagic marine ecosystems. Rapp. P.-V. Réun. Cons. Int. Explor. Mer, 173: 60-65.

Prado-Fiedler, R. 2000. Distribución de la biomasa fitoplanctónica y productividad primaria máxima de fiordos y canales australes $\left(47-50^{\circ} \mathrm{S}\right)$ en octubre 1996. Cienc. Tecnol. Mar, 23:15-24.

Pridle, J., R. Leakey, C. Symon, M. Whitehouse, D. Robins, E. Murphy \& N. Owen. 1995. Nutrient cycling by Antarctic marine microbial plankton. Mar. Ecol. Progr. Ser., 116: 181-198.

Quiñones, R.A., T. Platt \& J. Rodríguez. 2003. Patterns of biomasa-size spectra from oligotrophic waters of the Northwest Atlantic. Progr. Oceanogr., 57: 405-427.

Rees, T.V.A., T.R. Larson, J.W.G. Heldens \& F.G.I. Huning. 1995. In situ glutamine synthetase activity in a marine unicellular alga (development of a sensitive colometric assay and the effect of nitrogen status on enzyme activity. Plant Physiol., 109: 1405-1410. 
Rodríguez, J. \& M. Mullin. 1986. Relation between biomass and body weight of plankton in a steady state oceanic ecosystem. Limnol. Oceanogr., 31: 361-370.

Rodríguez, L., V. Marín, M. Farías \& E. Oyarce. 1991. Identification of an upwelling zone by remote sensing and in situ measurements. Mejillones del Sur Bay (Antofagasta, Chile). Sci. Mar., 55: 467473.

Rodríguez, J., J. Tintoré, J.T. Allen, J.M. Blanco, D. Gomis, A. Reul, J. Ruiz, V. Rodríguez, F. Echevarría \& F. Jiménez-Gómez. 2001. Mesoscale vertical motion and the size structure of phytoplankton in the ocean. Nature, 410: 360363.

Silva, N., H. Sievers \& R. Prado. 1995. Características oceanográficas y una proposición de circulación, para algunos canales australes de Chile entre $41^{\circ} 20^{\prime} \mathrm{S}, 46^{\circ} 40^{\prime} \mathrm{S}$. Rev. Biol. Mar., Valparaíso, 30(2): 207-254.

Silva, N., C. Calvete \& H. Sievers. 1997. Características oceanográficas físicas y químicas de Canales Australes Chilenos entre Puerto Montt y Laguna San Rafael (Crucero CIMAR - FIORDO 1). Cienc. Tecnol. Mar, 20: 23-106.

Slawyk, G. \& M. Rodier. 1986. Glutamine synthetase activity in Chaetoceros affinis (Bacillariophyceae): comparison with other estimates of nitrogen utilization during nutrient perturbation. J. Phycol., 22: $270-275$.

Slawyk, G. \& M. Rodier. 1988. Biosynthetically active glutamine synthetase in the marine diatom Phaeodactylum tricornutum: optimization of the forward-reaction assay. Mar. Biol., 97: 269-274.

Slawyk, G., B. Coste \& Y. Collos. 1997. Isotopic and enzymatic analyses of planktonic nitrogen utilization in the vicinity of Capes Sines (Portugal) during weak upwelling activity. Deep-Sea Res., 44: 1-25.

Sosik, H.M. \& B.G. Mitchell. 1991. Absorption, fluorescence, and quantum yield for growth in nitrogen-limited Dunaliella tertiolecta. Limnol. Oceanogr., 36: 910-921.

Recibido: 5 mayo 2006; Aceptado: 13 abril 2007
Sprules, W. \& M. Munawar. 1986. Plankton size spectra in relation to ecosystem productivity, size, and perturbation. Can. J. Fish. Aqua. Sci., 43: 1789-1794.

Syret, P.J. 1981. Nitrogen metabolism in microalgae. Can. Bull. Fish. Aqua. Sci., 210: 182-210.

Takabayashi, M., F.P. Wilkerson \& D. Robertson. 2005. Response of glutamine synthetase to transcription and enzyme activity to external nitrogen sources in the diatom Skeletonema costatum (Bacillariophyceae). J. Phycol., 41: 8494.

Timmermans, K.R., W. Stolte \& H.J.W. de Baar. 1994. Iron-mediated effects on nitrate reductase in marine phytoplankton. Mar. Biol., 121: 389-396.

Treguer, P. \& G. Jacques. 1992. Dynamics of nutrients and phytoplankton and fluxes of carbon, nitrogen and silicon in the Antarctic Ocean. Polar Biol., 12: 149-162.

Tyrrel, T. 1999. The relative influences of nitrogen and phosphorus on oceanic primary production. Nature, 400: 525-531.

Ulloa, O., R. Escribano, S. Hormazábal, R.A. Quiñones, R.R. González \& M. Ramos. 2001. Evolution and biological effects of the 1997-98 El Niño in the upwelling ecosystem off northern Chile. Geophys. Res. Lett., 28: 1591-1594.

Vergara, J., J. Berges \& J. Falkowski. 1998. Diel periodicity of nitrate reductase activity and protein levels in the marine diatom Thalassiosira weissflogii (Bacillariophyceae). J. Phycol., 34: 952-961.

Wilkerson, F.P. \& G. Grunseich. 1990. Formation of blooms by the symbiotic ciliate Mesodinium rubrum: the significance of nitrogen uptake. J. Plankton Res., 12: 973-989.

Witek, Z. \& A. Krajewska-Soltys. 1989. Some examples of epipelagic plankton size structure in high latitude oceans. J. Plankton Res., 11: 11431155 .

Zar, J.H. 1984. Biostatistical Analysis. Prentice Hall, New Jersey, 718 pp. 